hearing from the investigator that their patient was a 'doctor shopper'. Only occasionally did a doctor indicate to the investigator that they asked their patients whether they were seeing other doctors.

\section{Prescribing benzodiazepines long-term}

All doctors in the study had prescribed benzodiazepines on a long-term basis. Over half of the doctors had prescribed benzodiazepines to one or more patients for a period of at least 12 months. One patient had been prescribed benzodiazepines for a 10 -year period.

\section{DISCUSSION}

While benzodiazepines are generally effective and safe drugs to use, there is a significant risk of a patient becoming dependent or experiencing withdrawal after a relatively short period of use. Furthermore, there is a small but significant group of patients in the community who abuse benzodiazepines.

The Royal Australian College of General Practitioners has produced a publication, called Anxiety and Insomnia: Think Twice Before Prescribing, which outlines principles of good management for the prescribing of benzodiazepines. ${ }^{1}$ It includes information on the management of anxiety and insomnia, withdrawal from benzodiazepines, and the prevention of dependence. There is also a section on drug misuse that discusses prescribing in relation to habitual drug users.

\section{REFERENCE}

1. Mant A, de Burgh S, Letton T, Shaw J. Anxiety and insomnia: think twice before prescribing. Melbourne: The Royal Australian College of General Practitioners, 1997. it

To obtain a copy of Recognising and Handling Patients Liable to Abuse Benzodiazepines (publication number TG199) write to the Duty Pharmacist, Pharmaceutical Services Branch, NSW Department of Health, PO Box 103, Gladesville, NSW 1675; or telephone (02) 9879 3214. The Duty Pharmacist is also able to supply doctors with written information to assist them with patients seeking other drugs of dependence.

\title{
HIV INFECTION, AIDS, HEPATITIS C, AND SEXUALLY TRANSMISSIBLE INFECTIONS IN AUSTRALIA: NATIONAL SURVEILLANCE RESULTS TO DECEMBER 1998
}

\section{Ann McDonald \\ National Centre in HIV Epidemiology and Clinical Research, Darlinghurst}

The third annual surveillance report HIV-AIDS, Hepatitis $C$ and Sexually Transmissible Infections in Australia Annual Surveillance Report 1999 was released in October 1999. ${ }^{1}$ The report, framed in the context of the third National HIV-AIDS Strategy 1996-97 to 1998-99, provides a comprehensive summary of current knowledge on the pattern of HIV infection, AIDS, hepatitis C, and sexually transmissible infections in Australia. It includes information on:

- time trends in diagnoses of those infections;

- incidence and prevalence in populations at higher or lower risk of HIV infection, such as gay and other homosexually-active men, indigenous people, people who have injected drugs, and people at risk through heterosexual contact only;

- patterns of treatment for HIV infection;

- patterns of risk behaviour for HIV and related infections.

The main findings are presented as text, supported by figures. The data are presented as tables and follow the main report. This article outlines key results from the report.

\section{TRENDS IN DIAGNOSES OF HIV INFECTION AND AIDS}

The annual number of diagnoses of AIDS in Australia has dropped from a peak of 950 cases in 1994 to an estimated 348 in 1998 (Figure 3). The annual number of diagnoses of HIV infection has also continued to decline, to around 660 in 1998. However, the number of documented cases of newly acquired HIV infection in 1993-1998 has remained stable at 150-200 infections per year, providing a lower limit to the number of cases of HIV transmission that have actually occurred in Australia each year. Allowing for undocumented cases, it is estimated that 450 cases of newly acquired HIV infection occur in Australia annually.

The number of people living with HIV infection in Australia was estimated to be 11,800 by the end of 1998 including 2,430 people living with AIDS. The number of people living with HIV infection in Australia is estimated to gradually increase to around 13,000 by the year 2003 .

Transmission of HIV in Australia continues to occur primarily through sexual contact between men. No evidence was available of recent change in rates of HIV transmission through male homosexual contact, nor any increase in the very low rates of transmission through 


\section{FIGURE 3}

HIV-AIDS DIAGNOSES IN AUSTRALIA, ADJUSTED FOR MULTIPLE REPORTING AND DELAYS

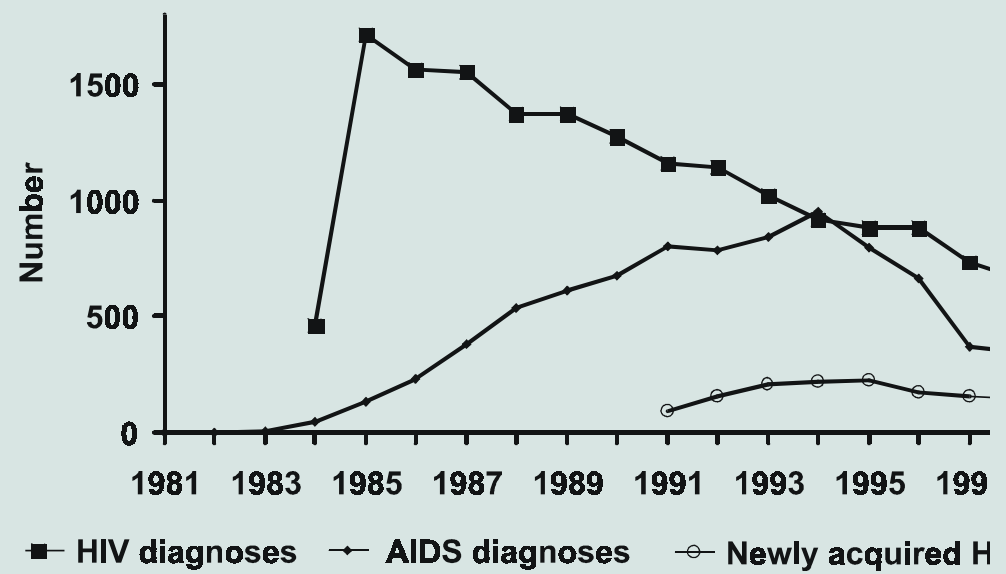

Source: State and Territory health authorities

\section{FIGURE 4}

SURVIVAL FOLLOWING AIDS DIAGNOSIS

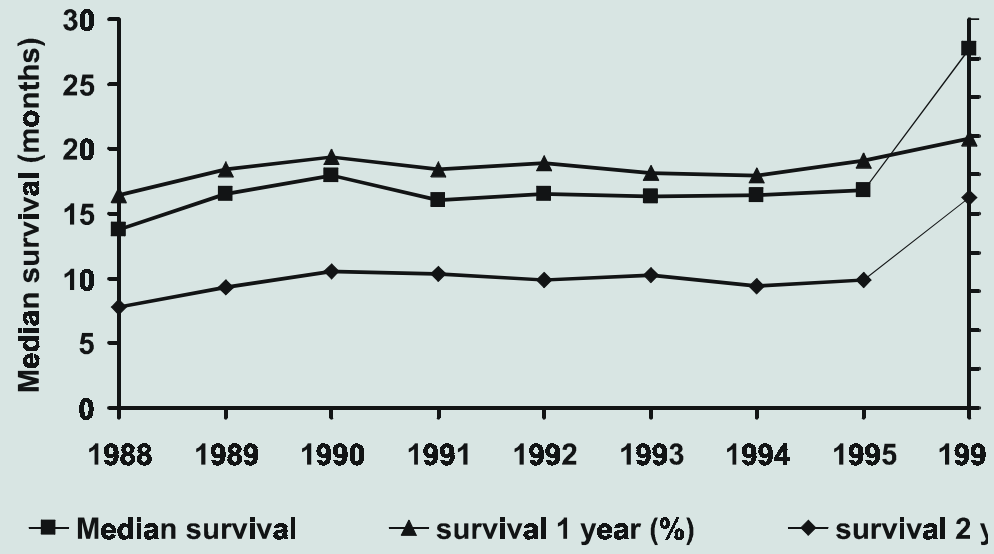

Source: State and Territory health authorities

injecting drug use or heterosexual contact.

In almost 50 per cent of 526 cases of HIV infection attributed to heterosexual contact in 1994-1998, infection was acquired through heterosexual contact in an overseas country with a high prevalence of HIV infection, or through heterosexual contact with a person from a high prevalence country, such as countries in sub-Saharan Africa, or countries in South East Asia such as Cambodia, Thailand and Myanmar.

Rates of HIV and AIDS diagnoses per capita differed little between indigenous and non-indigenous people. Among indigenous people, however, a higher percentage of diagnoses occurred in women and a higher percentage of infections were acquired heterosexually.

\section{EFFECT OF ANTIRETROVIRALTREATMENT ON AIDS DIAGNOSES}

It is now clear that the fall in AIDS incidence observed from 1994 has been substantially accelerated by improvements in therapy. Over 1,000 fewer cases of AIDS have occurred than would have been expected had there been no improvement in therapy for HIV infection.

Median survival following AIDS has increased significantly from 19.7 months among people diagnosed in 1995 to 27.7 months among those diagnosed in 1996 (Figure 4).

Over 40 per cent of AIDS cases in 1998, up from 20 per cent in 1994, occurred in people who were newly diagnosed with HIV infection within the preceding three 


\section{FIGURE 5}

HIV AND HCV PREVALENCE IN NEEDLE AND SYRINGE PROGRAMS

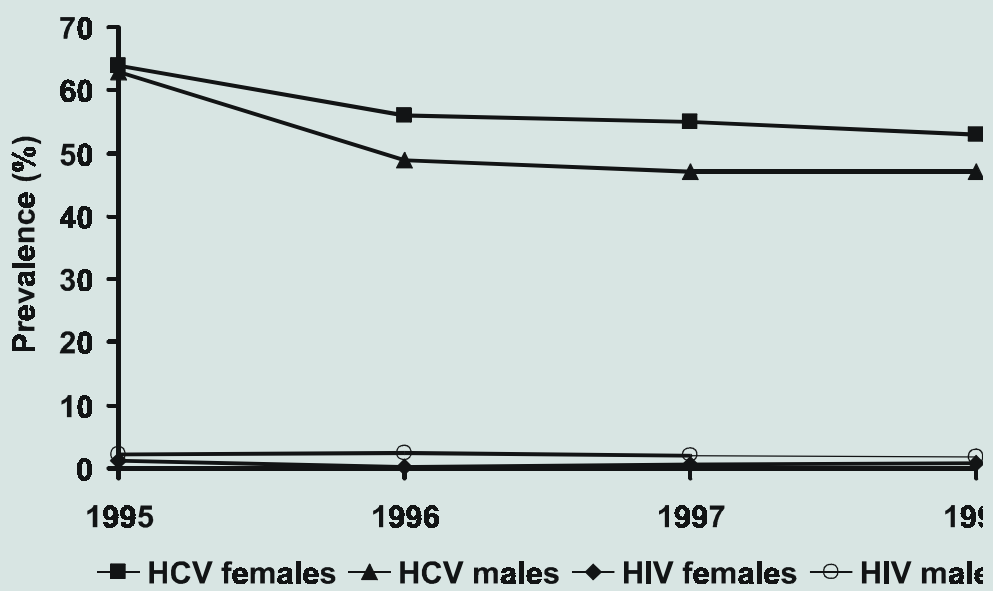

Source: collaboration of Australian needle and syringe programs

months. These people were therefore unable to benefit from antiretroviral therapy or prophylaxis for opportunistic infection. As a consequence 1998 saw an increase, for the first time since the $1980 \mathrm{~s}$, in the proportion of AIDS diagnoses presenting as Pneumocystis carinii pneumonia.

\section{Trends in HIV risk behaviour}

Surveys carried out among gay and other homosexually active men in Sydney indicate an increase in the percentage of men who report unprotected anal intercourse with casual partners, from 14 per cent in 1996 to 18 per cent in 1998. Surveys carried out among gay and other homosexually active men in Adelaide, Brisbane, Melbourne and Perth show similar levels of unsafe sexual behaviour with casual partners.

The number of rectal isolates of gonorrhoea increased among men in New South Wales, from 72 in 1997 to 158 in 1998, suggesting a recent increase in sexual risk among gay and other homosexually-active men.

Surveys of 17-19 year old first-year university students show increasing levels of condom use with casual partners.

\section{TRENDS IN DIAGNOSES OF HEPATITIS C INFECTION}

Hepatitis C was the most frequently reported notifiable infection in Australia in 1998. A substantial increase was observed in the number of diagnoses reported among people aged less than 20 years.

The number of cases of newly acquired hepatitis $C$ infection increased sharply in 1998, attributable to increased efforts to identify and report these cases.

Transmission of hepatitis C continued at high levels among people who report injecting drug use. There has been no further decline in prevalence following that observed among people attending needle and syringe programs in 1996 (Figure 5).

\section{TRENDS IN DIAGNOSES OF SEXUALLY TRANSMISSIBLE INFECTIONS}

Reported cases of gonorrhoea increased in 1998, as did reported cases of syphilis. These trends may be partially attributable to changing diagnostic methods and case definitions, and partly to real shifts in prevalence or incidence of these infections.

Indigenous people continue to be diagnosed with these infections at much higher rates than non-indigenous people.

\section{REFERENCE}

1. National Centre in HIV Epidemiology and Clinical Research. HIV/AIDS, Hepatitis C and Sexually Transmissible Infections in Australia Annual Surveillance Report 1999. Sydney: National Centre in HIV Epidemiology and Clinical Research, University of New South Wales, 1999. it

The 1999 Annual Surveillance Report is accessible through the Web site www.med.unsw.edu.au/ nchecr. Copies of the report can be obtained by writing to the Epidemiology Section at the National Centre in HIV Epidemiology and Clinical Research, Level 2, 376 Victoria Street, Darlinghurst, NSW 2010; by telephone: (02) 9332 4648; by facsimile: (02) 93321837 ; or by email at: recept@nchecr.unsw.edu.au. 